\title{
A PESQUISA NA INICIAÇÃO CIENTÍfICA DE ENSINO MÉDIO E O JOVEM ESTUDANTE: uma visão semiótica e auto-organizada
}

Alan Rodrigo Antunes

Márcia Regina Canhoto de Lima

\section{Resumo}

Nesta pesquisa são apresentadas as percepções dos jovens estudantes que vivenciaram a Iniciação Científica (I.C.) de Ensino Médio (E.M.) em uma instituição federal de ensino. Participaram 13 exorientandos em um desenho longitudinal de 8 anos. Usou-se como referencial teórico a Semiótica de Charles S. Peirce, a Teoria da Auto-organização de Michel Debrun e a Sociologia da Juventude. Foi caracterizada como uma pesquisa na ação, fundamentada nas ideias de Lawrence Stenhouse e teve como principais objetivos: analisar o processo educacional em um ambiente de I.C. de E.M.; e apontar as percepções dos sujeitos da pesquisa em relação à formação proporcionada pelo aprendizado compartilhado entre orientador e jovem estudante. Sendo assim, o processo educacional apresentou valorização da conclusão do E.M. e da apropriação de novos conhecimentos; e aporte significativo da I.C. para as disciplinas escolares.

Palavras-chave: cultura juvenil; iniciação científica; ensino médio.

\section{RESEARCH IN SCIENTIFIC INITIATION OF HIGH SCHOOL AND YOUNG STUDENT:}

\author{
a semiotic and self-organized view
}

\begin{abstract}
In this research, the perceptions of young students who experienced Scientific Initiation (I.C.) of High School (E.M.) in a federal educational institution are considered. 13 former supervisors participated in an 8-year longitudinal design. Use Charles S. Peirce's Semiotics, Michel Debrun's Theory of SelfOrganization and the Sociology of Youth as a theoretical framework. It was characterized as a research in action, based on the ideas of Lawrence Stenhouse and had as the main objectives: to analyze the educational process in an environment of I.C. of E.M.; and they point out as perceptions of the research subjects in relation to the training provided by the learning shared between tutor and young student. Thus, the educational process showed appreciation for the conclusion of the E.M. and the appropriation of new knowledge; and a significant contribution from the I.C. to school subjects.
\end{abstract}

Keywords: youth culture; scientific research; high school.

\section{INVESTIGACIÓN EN INICIACIÓN CIENTÍFICA DE ESCUELA SECUNDARIA Y ESTUDIANTE JOVEN: una vista semiótica y autoorganizada}

Resumen

En esta investigación se presentan las percepciones de los jóvenes estudiantes que experimentaron la Iniciación Científica (I.C.) de High School (E.M.) en una institución educativa federal. Trece ex alumnos participaron en un diseño longitudinal de 8 años. La semiótica de Charles S. Peirce, la teoría de la 
autoorganización de Michel Debrun y la sociología de la juventud se utilizaron como referencia teórica. Se caracterizó como una investigación de acción, basada en las ideas de Lawrence Stenhouse y tenía como objetivos principales: analizar el proceso educativo en un entorno de I.C. de E.M.; y señalar las percepciones de los sujetos de investigación en relación con la capacitación brindada por el aprendizaje compartido entre el tutor y el joven estudiante. Así, el proceso educativo mostró aprecio por la conclusión de la E.M. y la apropiación de nuevos conocimientos; y una contribución significativa del I.C. a las materias escolares.

Palabras clave: cultura juvenil; iniciación Científica; escuela secundaria.

\section{INTRODUÇÃO}

No presente artigo, busca-se exaltar a pesquisa no âmbito escolar, especificamente de Ensino Médio (E.M.), relacionando-a ao ensino e proporcionando uma discussão sobre o papel que a escola potencialmente possui nesse campo. Os programas de Iniciação de Científica (I.C.) de E.M. apresentam-se como uma das formas de contribuir para a introdução de jovens estudantes em ambientes de pesquisa que vêm se institucionalizando, inicialmente nos laboratórios das Universidades e nos Centros de Pesquisas brasileiros, e depois com maior intensidade nos Institutos Federais de Educação, Ciência e Tecnologia (I.Fs.).

A I.C. é geralmente realizada por estudantes ligados às instituições do Ensino Superior que começaram a receber bolsas de I.C. do $\mathrm{CNPq}^{1}$ em 1951; já as Bolsas de Iniciação Científica (PIBIC) Júnior começaram a ser oferecidas a estudantes do Ensino Fundamental no ano de 2003; e em 2010 iniciou-se o oferecimento de bolsas (PIBIC-EM) aos estudantes do E.M., interessados em realizar pesquisas nas Universidades e Institutos de Pesquisa.

Contudo, as pesquisas publicadas ${ }^{2}$ com objetivo de analisar a I.C. de E.M. apontavam que os orientadores não eram os professores dos estudantes, mas professores universitários que não estavam em contato direto com os alunos e/ou disponibilizaram as bolsas PIBIC-EM, conseguidas por meio de editais provenientes do CNPq em parceria com as instituições de ensino superior. Apresentavam também dados descritivos, importantes, porém não permitiam uma compreensão crítica que possibilitasse analisar como os saberes profissionais intervêm nesse processo e como as inovações têm provado melhorias no âmbito educacional.

No entanto, um número expressivo de pesquisas no campo da juventude, em especial sob a ótica da Sociologia da Juventude (PAIS, 1990, 1993, 1998, 2009, 2012; SPOSITO, 1993; PERALVA, 1997; FEIXA, 1998, 2003; CARRANO 2011; DAYRELL, 1996, 2002; DAYRELL, CARRANO e MAIA, 2014), tem investigado a juventude no E.M. e trazido para a discussão no campo acadêmico o desafio de trabalhar com os jovens estudantes em diferentes aspectos como: a crítica à noção de juventude como um objeto pré-construído; a participação e o protagonismo do jovem nas tomadas de decisões; a reflexão sobre uma visão negativa na qual a juventude é vista como um problema; o jovem como sujeito de direito; a relação entre a adolescência e a juventude; a juventude e o mercado de trabalho; o questionamento sobre as definições da

1 Os dados aqui apresentados podem ser acessados no seguinte enderece eletrônico: disponível em: <http://memoria.cnpq.br/web/guest/dados_abertos>. Acesso em: 06 jul. 2019.

2 Foram analisados 08 artigos, caracterizados como pesquisas sobre a IC de EM, publicados em 7 periódicos, selecionados de 425 artigos, 4 dissertações e 3 teses publicados entre 2004 e 2019. Para os artigos não se estabeleceu restrição nas áreas do Sistema Qualis da Capes e no campo de atuação. Para as dissertações e teses também não houve restrição no campo de atuação. Segue para consulta os textos analisados: Ferreira, 2003; Filipecki, Barros e Elia, 2006; Heck, 2012; Civiero e Sant'ana, 2013; Nascimento et al., 2015; Noronha et al., 2015; Massola, 2016; Oliveira e Bianchetti, 2018a, 2018b. 
juventude em uma perspectiva etária; a exaltação de ser jovem e a ausência de políticas públicas; e o acesso aos bens materiais e culturais. Porém, não há pesquisas ${ }^{3}$ sobre a Sociologia da Juventude tendo como objeto de estudo a I.C. no E.M. por ser um campo relativamente novo e que carece de estudos em diferentes contextos (NUNES; WELLER, 2003). Partindo desse ponto de vista, entende-se que a presente pesquisa aponta caminhos que poderão trazer contribuições para o tema ao considerar as perspectivas dos estudantes.

Sendo assim, um novo significado da juventude emerge do conjunto de transformações pelas quais a sociedade contemporânea está passando. Nesse sentido, o jovem, durante séculos, foi tratado como sujeito social que pensava e sentia os problemas sociais, políticos e econômicos como os adultos e as pessoas mais velhas. Foi somente a partir do século XX que a ideia de sujeito imaturo, irresponsável e insensato, que necessitava amadurecer para tornar-se um sujeito de fato, passou a ser questionado e discutido. $\mathrm{Na}$ esteira desse pensamento, Marília Sposito (1993, p. 38) chama atenção para estudos que tratam a juventude na educação como uma categoria "[...] em que os critérios que a constituem enquanto sujeitos são históricos e culturais", estes estudos permitiram "[...] a visibilidade desse segmento na sociedade brasileira nos últimos anos". A autora chama atenção para a utilização de critérios de faixa etária sem "[...] considerar as condições sociais em que se opera o desenvolvimento dos ciclos de vida [...]". Da mesma forma, Angelina Peralva (1997, p. 16) reflete sobre o papel social do jovem, ao longo da história, e traz para a discussão uma interpretação da juventude enquanto fase particular da vida, como uma construção cultural, na qual a "cristalização social das idades da vida é múltipla e convergente" e essencial no âmbito da família, do trabalho, da escola e sofre ação do Estado, portanto também administrativa. Somam-se a tais interpretações as ideias de José Machado Pais (1990, p. 140), que trata da representação corrente da juventude como uma cultura juvenil unitária e da questão principal colocada à sociologia da juventude, que "[...] é a de explorar não apenas as possíveis ou relativas similaridades entre jovens ou grupos sociais de jovens [...], mas também - e principalmente - as diferenças sociais que entre eles existem".

Desse modo, a juventude ganhou um papel cada vez mais relevante na Sociologia, com reflexões, análises e produções acadêmicas que buscam compreender quem é o sujeito "jovem". Nesse sentido, pensar em uma Sociologia da Juventude é considerar o jovem como objeto de pesquisa e como um ser social num contexto de relações (escola, família, emprego, grupos culturais, redes sociais) das quais fazem parte. Para tanto, as noções e percepções referentes à juventude são marcadas e estabelecidas por aspectos históricos e sociais que mudam com o tempo e são fortemente marcadas pela cultura, classe social, gênero, etnia, raça e diferentes sociedades. Contudo, é preciso considerar as diversas variáveis que fazem referência a esse ramo de estudo para poder conceituar e compreender de forma mais plausível o jovem e, sem dúvida, integrá-los à sociedade.

Por conseguinte, estudos científicos (SPOSITO, 2005, 2007; FEIXA, 1998, 2003; MARTINS e CARRANO, 2011; CARRANO, 2011; DAYRELL e CARRANO, 2014) apontam para o fato de que a juventude não é homogênea e as configurações sociais em torno dela não se constituem abstratamente, mas se orientam conforme as interações vivenciadas pelos jovens no interior de contextos específicos. O entendimento da juventude como uma categoria homogênea

\footnotetext{
${ }^{3}$ Realizou-se uma busca nas bases de dados scholar.google.com.br, scielo.br, periodicos.capes.gov.br e bdtd.ibict.br com os termos "Sociologia da Juventude", "Ensino Médio", "Iniciação Científica" e "Jovem" e não foram encontradas pesquisas que tratavam da problemática. Os termos foram pesquisados de forma isolada e combinada.
} 
precisa ser desconstruído e implica em admitir que a Condição Juvenil origina-se em valores estreitamente ligados a um ponto de vista social e histórico do Brasil, sofrendo influência das culturas juvenis, dos grupos sociais em que convivem e dos lugares em que transitam.

Nessa perspectiva, três dimensões são apontadas por Juarez Dayrell e Paulo Carrano (2014, p. 115-119) para compreender o jovem: as Culturas Juvenis, a Sociabilidade e o Tempo e Espaço. As Culturas Juvenis são caracterizadas pela forma de comunicação, atitudes, comportamentos, gostos e posicionamento de determinado grupo de jovens perante a sociedade e a si mesmos. Assim, as Linguagens Culturais - como a música, a dança, o vídeo, o corpo e seu visual - são mediadores que permitem os jovens se agruparem, dando a eles a possibilidade de serem produtores culturais e não apenas fruidores. A Sociabilidade refere-se à relação do indivíduo com seus pares, ou seja, é a dimensão na qual o jovem se relaciona com quem ele possui afinidades. Isso pode estar presente nos momentos de lazer e também nos espaços institucionais, como no trabalho e na escola. Essa dinâmica de relações é um momento de descobertas, experimentações e escolhas que demandam autonomia. Por último, a dimensão de Tempo e Espaço dá significado ao lugar que os jovens frequentam e à maneira como eles vivenciam e gerenciam o tempo em diferentes situações. Essas configurações espaciais estão dotadas de interações afetivas e simbólicas, carregadas de sentidos.

Ademais, propõem-se possibilidades de interação teórico-metodológico no diálogo com a Semiótica ou Lógica Geral dos Signos, de Charles S. Peirce ${ }^{4}$ para investigar o cotidiano escolar. A fenomenologia peirceana é uma ciência que fornece noções capazes de descrever e ordenar toda e qualquer experiência. Tal perspectiva é importante, pois permite uma análise por meio da interação que permite conhecer a conexão entre os sujeitos e o saber, como se desencadeia e se mantém essa relação no processo educacional. Atrelado a isso, em Peirce (2012), a investigação do sujeito debruça-se sobre um indivíduo social e necessita humanizar-se, porém pela mediação dos signos ${ }^{5}$, incluindo a mediação da linguagem, a qual só tem significação na medida em que se choca com o vivido, o percebido, e não se trata de uma questão de definir a priori, mas de observar o que experimentamos em um processo em constante transformação.

Por certo, a grande contribuição da Semiótica Peirceana está em uma perspectiva na qual a escola e o jovem estudante não podem se submeter às propostas e aos parâmetros globais sustentados em teorias deterministas, mas em processos e engendramentos baseados em uma perspectiva da Sociologia da Juventude e não em uma perspectiva biológica. Esta compreende a juventude sob um viés naturalista e universal, como um estágio da vida marcado fortemente pela idade e por características próprias como rebeldia, revolta e insensatez. Nesse sentido, Pais (1990, p. 146) cita os estudos de Reuter e Mead que "[...] vieram por definitivamente em causa as teses então dominantes, que se limitavam a considerar a adolescência um corolário inevitável da maturação biológica e psicológica". A juventude vista apenas como uma etapa biológica do desenvolvimento humano, como uma fase de transição e preparação para a vida adulta, não reconhece os anseios, as necessidades e, sem dúvidas, as culturas juvenis, que os diferenciam e os potencializam para pensar e agir sobre e com o mundo e os adultos. Faz-se necessário desconstruir a noção homogênea de juventude, que ignora as singularidades e diversidades

\footnotetext{
${ }^{4}$ Charles Sanders Peirce (1839-1914) compreende fenomenologia como uma ciência que fornece noções capazes de descrever e ordenar toda e qualquer experiência, por meio de processos de significação, ou seja, transformação de um signo em outro signo, a semiose. (PEIRCE, 1974, 2012).

${ }^{5}$ Segundo Peirce (2012, p. 46) "um signo, ou representamen, é aquilo que, sob certo aspecto ou modo, representa algo para alguém. Dirige-se a alguém, isto é, cria, na mente dessa pessoa, um signo equivalente, ou talvez um signo mais desenvolvido".
} 
presentes nos diversos tempos e espaços do ser jovem, e conceber esses sujeitos como atores do seu processo de formação nas tramas das relações sociais. Por certo, ao considerar os anseios e as expectativas dos jovens, as ações educativas estarão instrumentalizadas para combater o que Carrano (2009, p. 159) chama de "incomunicabilidade entre os sujeitos escolares".

Com efeito, uma das possibilidades de abordar e investigar a I.C. de E.M. - entendida como parte integrante do cotidiano escolar e tendo a noção de juventude como uma representação social, em uma visão Semiótica - é a Teoria da Auto-organizaçao ${ }^{6}$ de Michel Debrun (1996); esta teoria soma-se às reflexões expostas até aqui e permite identificar o resultado de um processo de ensino e aprendizagem que busca ser criativo e rico. Debrun (1996) desenvolveu uma sistematização de ideias sobre a Auto-organização, sendo que esta poderia acontecer quando se desenvolve uma interação sem supervisor onipotente, a partir do encontro entre sujeitos em um sistema, por exemplo, no processo de orientação de I.C.. Essa interação tem a potencialidade de levar à constituição de uma forma ou à reestruturação de uma forma já existente.

Essa forma é o que se pretende encontrar e analisar, na presente pesquisa, sob três aspectos presentes na teoria de Debrun (1996), considerados como signos em um processo de semiose que caracterizam a interação: o corte temporal, atratores e ruidos. O processo de interação exige a ação de atratores e/ou ruidos durante a própria interação dos elementos envolvidos. Por exemplo, o tema de pesquisa pode funcionar como um atrator, assim como o desenvolvimento de um software, a possibilidade de encontrar a cura para uma doença, dentre outras inúmeras possibilidades em um processo de orientação de I.C.. O atrator, dessa forma, seria um elemento comum ou algo que despertaria a atenção e o interesse dos sujeitos para os quais todos os esforços seriam direcionados. Nesse mesmo sentido, um ruído seria um algo novo surgido no processo, provocando uma reorganização ou uma modificação, e não uma destruição. Por exemplo, na análise dos dados de uma pesquisa surgiriam dúvidas em relação às respostas dos participantes da pesquisa que não poderiam ser sanadas com as informações coletadas. Contudo, essa perturbação levaria a tomar a decisão de realizar entrevistas de verificação com os sujeitos da pesquisa e permitiria a finalização da análise dos dados e não o fracasso da pesquisa.

Outrossim, faz-se necessário permitir a emergência das potencialidades dos estudantes, o que necessita identificar as suas práticas atuais como algo novo, pressupondo um corte com o passado, ou seja, o corte temporal, descrito por Debrun (1996), que exige um trabalho de si sobre si. Contudo, esse corte não desconsidera o já vivido e alimenta novas possibilidades como expectativas dos sujeitos.

Nesse ínterim, a Teoria da Auto-organização possibilita identificar elementos (corte temporal, ruídos e atratores) presentes na interação que permitem dizer qual o resultado e o impacto da I.C. de E.M. em um processo de orientação. Contudo, não seria possível utilizar tal teoria sem caracterizar os jovens estudantes por meio da Sociologia da Juventude e o processo educacional como possuidor de uma linguagem, algo próprio do sujeito, e modificado pela cultura e pelo tempo histórico, livres das amarras deterministas.

Logo, como já relatado, raras são as pesquisas com o propósito de discutir o papel da I.C. de E.M. na formação do jovem estudante. Isto posto, Dayrell e Carrano (2014) atentam para a necessidade de reconhecer experiências, saberes e identidades culturais como condição para o

\footnotetext{
"O termo "auto" significa "ele mesmo", no sentido de que o resultado de um processo ou a construção de um projeto ou trabalho resulte em algo criado pelos próprios envolvidos, e não como algo já pronto e determinado.

${ }^{7}$ Nesse sentido um orientador de I.C. aturaria como um "supervisor" que se propõe à interlocução, para possibilitar um aprendizado no qual a criatividade e a novidade estariam presentes.
} 
relacionamento e para o diálogo no cotidiano escolar. E qualquer mudança desse entendimento deve ser resultante de alterações estruturais, que permitam enfrentar as diversidades e as desigualdades sociais.

Tendo em vista a discussão realizada, a presente pesquisa tem como objetivo analisar o processo educacional na visão dos jovens estudantes em um ambiente de I.C. de E.M. Isto supõe um aporte significativo à temática de estudo, já que se propõe a comprovar a percepção dos jovens estudantes de um modo longitudinal.

\section{METODOLOGIA}

A metodologia escolhida para esta investigação é de natureza qualitativa, caracterizandose como pesquisa na ação fundamentada nos pressupostos de Stenhouse (1993). Constituiu-se importante porque a investigação na ação permite privilegiar tanto o aspecto científico quanto o educacional, e, também, não se submete a generalizações psicoestatísticas, mas a análises interpretativas e críticas dos dados coletados. Isso permitiu a utilização das teorias científicas relatadas anteriormente, como a identificação dos atratores e ruídos no processo educacional; estas teorias permitiram caracterizar as vivências e os modos de pensar e agir dos jovens estudantes.

Stenhouse (1993) adverte que a investigação, para resultar útil aos professores, exige que estes testem em suas práticas a suas implicações teóricas. Sendo assim, traz a figura do professorpesquisador que tem o papel de descobrir hipóteses, cuja testagem podem conduzir ao aperfeiçoamento da prática e servir como uma rota alternativa para a geração da teoria.

Ademais, a percepção do vivido pela mediação da linguagem, atrelada à figura do professor-investigador, consente uma análise por meio da inferência, que segundo Laurence Bardin, caracteriza a análise qualitativa por meio da interpretação de elementos em termos de importância e qualidade e não de freqüência. Por conseguinte, faz-se "[...] necessário distanciarmo-nos da crença sociológica na significação da regularidade. O acontecimento, o acidente e a raridade, possuem, por vezes, um sentido muito forte que não deve ser abafado". (BARDIN, 1997, p. 116).

Perante o exposto, e na concordância com Stenhouse (1993), compreende-se que a investigação é uma indagação sistemática e autocrítica e deve ser feita na própria prática pedagógica docente, pois a fragilidade da pesquisa no seio escolar reside na sua desconexão com a realidade concreta e na sua falta de comprovação na ação.

\section{Desenho da pesquisa na ação vivenciada}

Com o propósito de qualificar a pesquisa na ação, o processo de orientação - baseado na Semiótica e na Auto-organização (PEIRCE, 2012; DEBRUN, 1996) e considerando as perspectivas dos jovens estudantes calcados na Sociologia da Juventude - contou com as seguintes fases em forma de espiral ${ }^{8}$ :

i. Escolha do tema de pesquisa e do desenvolvimento da problemática tendo como ponto de partida o interesse tanto do orientador quanto dos orientandos, já que um "trabalho de si sobre si" necessita de motivação para os envolvidos no processo;

\footnotetext{
${ }^{8}$ As fases de um processo educativo em espiral pressupõem não a repetição circular e repetitiva das etapas, mas uma reflexão constante do que foi realizado para que uma nova etapa possa ser iniciada. O propósito de tal desenho é a reflexão permanente do que foi feito para que um aprendizado novo e criativo possa surgir.
} 
ii. Levantamento bibliográfico e histórico sobre o tema de pesquisa; científica;

iii. Estudo e capacitação do orientando(s) em relação ao método científico e a escrita

iv. Problematização, por meio de uma nova reflexão sobre o tema de pesquisa, e determinação da continuação da pesquisa, com a definição da metodologia e das técnicas de coleta de dados ou a volta ao início do processo;

v. Realização dos procedimentos legais, Comitê de Ética, quando fosse necessário;

vi. Revisão da problemática e da metodologia para a aplicação e coleta de dados;

vii. Descrição e tabulação dos dados coletados;

viii. Análise dos dados coletados sempre amparado pelo problema de pesquisa;

xix. Escrita final com ênfase na interação entre orientador e orientado por meio de uma reflexão sobre todo o processo, e não apenas sobre os resultados da pesquisa.

As orientações aconteceram semanalmente por um período de pelo menos 12 meses. Havia também a participação mensal desses jovens estudantes no Grupo de Estudo (GECET) coordenado pelo orientador.

\section{Participantes: jovens estudantes}

Participaram 13 jovens estudantes sendo ( 5 homens e 8 mulheres). Todos estudavam na mesma escola federal de Ensino Médio e Técnico Integrado (E.M.T.I.), sendo que 10 possuíam uma renda familiar abaixo de 2 salários mínimos ${ }^{9}$, e 3 uma renda abaixo de 4 salários mínimos. No início da orientação, que ocorreu em períodos distintos para cada estudante entre os anos de 2011 e 2019, 6 participantes se encontravam no primeiro ano do E.M. e 7 no segundo ano do mesmo nível de ensino, com uma idade média de 16 anos. Eles responderam os questionários e foram entrevistados após a conclusão da orientação no $1^{\circ}$ semestre de 2020 , não necessariamente após a conclusão do E.M.T.I. Nesse período, 7 deles estavam concluindo o E.M.T.I., 5 cursavam o Ensino Superior (E.S.), em diversas áreas (Medicina, Educação Física, Direito, Psicologia), e 2 atuavam profissionalmente (1 desses cursava concomitantemente o E.S.). Como dado a destacar, todos receberam bolsas PIBIC-EM e apresentaram os resultados das pesquisas nas feiras de I.C., tanto da própria instituição quanto em feiras externas.

\section{Desenho e procedimentos}

Tendo em vista o exposto, a investigação foi estruturada em três etapas, buscando a triangulação das informações obtidas pela coleta dos dados: a) por meio do diário de campo (ALVES-MAZZOTTI; GEWANDSzNAJDER, 1999) para o registro das atividades de orientações realizadas no período de 2011 à 2019; b) questionário online, submetido a todos os jovens ex-orientandos durante o primeiro semestre de 2020; e c) entrevista, baseada na lógica da entrevista reflexiva (SZYMANSKI; ALMEIDA; PRANDINI, 2011), que teve como objetivo melhor compreender as respostas dadas pelos estudantes nos questionários.

O registro do diário de campo acontecia após cada orientação e buscava mais do que guardar informações, ou seja, registravam-se reflexões cotidianas além de descrições e observações pontuais. Esse instrumento permitiu direcionar o percurso da pesquisa na ação e fornecer elementos importantes para uma análise contínua das etapas de orientação.

\footnotetext{
${ }^{9}$ O salário mínimo levado em consideração foi o vigente no momento da pesquisa, ou seja, o valor de R\$998,0.
} 
O questionário, respeitando o rigor exigido por Lakatos e Marconi (2010), continha questões abertas e fechadas e foi desenvolvido por meio das seguintes etapas: a) versão preliminar com base na problemática; b) comprobação da versão preliminar do questionário; c) aplicação-piloto do questionário; e d) construção da versão final.

Para validação do questionário quanto à abrangência, pertinência e adequação, este foi submetido à apreciação de quatro especialistas (chamado de painel) em Educação, com título de doutorado e com experiência em I.C. de E.M.. Na elaboração da versão final, foram acatadas as seguintes modificações sugeridas por esse painel: a) distribuição das questões de forma aleatória, com o intuito de eliminar respostas semelhantes e de levar o respondente a refletir de forma mais intensa sobre os temas; b) dados como nome, endereço de e-mail e atuação profissional e/ou acadêmica foram inseridos fora das questões; c) diminuir o número de itens dos 25 originais para 21.

A versão corrigida foi avaliada por quatro pesquisadores orientadores, também, com experiência em I.C. de E.M. Nessa oportunidade, um pesquisador sugeriu inserir um item que dava aos respondentes a possibilidade de incorporar sugestões para a I.C. e/ou para orientador. Dessa forma, na versão final foi introduzida uma questão voltada para esse assunto.

Sendo assim, o questionário foi revisto gerando a versão final, e continha uma breve descrição do estudo e o convite de participação, assim como o TCLE. O questionário apresentou quatro grandes eixos que contemplavam elementos basilares das teorias norteadoras da pesquisa: a) motivação do respondente, com 7 itens; b) formação como estudante, com 4 itens; b) formação como pessoa, com 3 itens; e c) objetivos da I.C., com 4 itens. As questões fechadas (seis no total) possuíam um item denominado de outros com a intenção de permitir ao respondente expressar a sua ideia, caso os itens de respostas apresentados não fizessem sentido para ele.

Por fim, as entrevistas foram realizadas no formato online (utilizou-se o Google Meet) e aplicadas em 4 sujeitos da pesquisa, sendo 2 homens e 2 mulheres. Eles apresentaram respostas nos questionários que, mesmo confrontadas com os registros no caderno de campo, exigiam mais detalhes para agrupá-las nas categorias de análises. O processo de realização das entrevistas considerou tais respostas e serviu para a elaboração do roteiro que continha 5 perguntas referentes a 2 eixos do questionário: formação como estudante e objetivos da I.C.. Foi desenvolvido por meio das seguintes etapas: a) elaboração do roteiro de entrevista; b) prévio contato e consentimento; c) realização da entrevista; d) transcrições das falas; e e) análise. Para compreender melhor o posicionamento dos estudantes, explorou-se a relação entre a percepção de contribuição da I.C. e as demais atividades vivenciadas na escola, e também a identificação dos elementos que haviam contribuído para a mudança de comportamento dos estudantes diante dos saberes escolares.

\section{Categorias de análise}

Em conformidade com o exposto, e com o objetivo de garantir confiabilidade e credibilidade aos resultados, realizou-se uma codificação dos extratos de textos mais significativos em cada um dos instrumentos, usando para isso padrões coincidentes cruzados.

Por meio da análise dos textos e das ideias coincidentes no tratamento dos cinco eixos temáticos presentes no questionário, das observações registradas no caderno de campo e das entrevistas, agrupou-se as informações em três categorias, sendo duas próprias do aporte teórico da auto-organizaçãa: i) formação como estudante; ii) corte temporal; e iii) atratores e ruidos. 
Dessa maneira, todos os 13 jovens ex-orientandos responderam o questionário disponibilizado em um endereço eletrônico e as entrevistas foram realizadas com quatro deles, como relatado anteriormente.

\section{RESULTADOS E ANÁLISES DOS DADOS}

Aqui apresentamos os resultados e as análises das contribuições/impactos da I.C. na trajetória dos jovens estudantes, sendo que todas as informações extraídas ${ }^{10}$ dos instrumentos de coletas de dados foram agrupadas nas três categorias de estudo apresentadas anteriormente e discutidas na sequência. Por meio da análise de padrões cruzados ${ }^{11}$ apresentamos extratos literais de textos, descrevendo aqueles mais significativos e coincidentes, bem como percentuais estatísticos para algumas respostas.

\section{Formação como jovem estudante}

O contato inicial com a I.C. de E.M., para grande maioria dos jovens $(76,9 \%)$, aconteceu por meio de um convite realizado pelo orientador e professor do E.M., e isso foi apontado, juntamente com a oportunidade de obter novos conhecimentos, como algo mais motivador/importante que a própria bolsa de estudo oferecida pelo PIBIC-EM. Tal constatação vai ao encontro das análises no que se refere aos objetivos da I.C., pois para esses jovens estudantes destacam-se as contribuições advindas do próprio processo de orientação, observadas pela ênfase dada à interação e às expectativas atingidas por meio da experiência e do conhecimento adquirido, elementos destacados também na contribuição atual para o que eles fazem, quer seja estudo ou trabalho. Vejamos:

JE2: [...] porque antes era como uma obrigação e agora vejo como uma forma de mudar para melhor a vida das pessoas, levando informação. [...] como criamos atividades e íamos à escola aplicar e contar histórias relacionadas ao tema, essa ambientação com clima escolar me ajuda atualmente, pois estou trabalhando em uma escola, então já meio que sei como funciona graças ao I.C. JE3: [...] porque antes para mim a I.C. era só o desenvolvimento de projetos, mas hoje em dia eu digo que a I.C. ajuda jovens a se tornarem pessoas. JE4: A I.C. e a conseguinte oportunidade de apresentar o trabalho em feiras de ciências desenvolveram minhas habilidades orais como estudante, além de me pôr em contato com temas específicos da Educação Física que eu não teria tido a oportunidade de aprender de outra maneira. JE5: Ajudou-me a compreender melhor a inserção das tecnologias na nossa sociedade e como observar de modo crítico como nos relacionamos com ela. JE6: [...] pois com ela meus conhecimentos foram aprimorados. Além disso, o aspecto de pesquisa é um fator benéfico, visto que se aprende como procurar por algo, como investigar, desenvolve-se leitura e escrita, pois bem, aprende-se a pesquisar! $\mathrm{E}$ isso contribui para a vida acadêmica. JE8: [...] pois com meu projeto obtive

\footnotetext{
10 A extração das respostas contidas nos questionários e nos diários de campo foram transcritas para um corpus textual utilizando o editor LibreOffice para depois ser processada pelo software Iramuteq (www.iramuteq.org) para uma análise lexicografia básica e multivariada. A partir desse ponto foram construídas as categorias de análises utilizando o software Excel por meio da identificação e do mapeamento de padrões de respostas.

11 Identificação de elementos (palavras, termos, sinônimos, comportamentos, atitudes) que aparecem de forma repetitiva e similar presentes nos instrumentos de coletas de dados.
} 
resultados tanto no meu crescimento acadêmico quanto pessoal e também adquiri novos conhecimentos que se tornaram essenciais. JE10: Apresentou tanto um conhecimento da situações do cartório e de um aprofundamento nas linguagens de programações. JE13: Que realmente precisa de muitas transformações tanto da população quanto dos políticos para mudar a realidade brasileira para os indígenas e afro-brasileiros. [...] como acadêmico estou envolvido em projetos de pesquisa, o que foi facilitado pela experiência prévia que tinha com a IC. JE11: [...] porque me ajudou a aprofundar e aplicar alguns conhecimentos de linguagem técnica. JE12: Como dito anteriormente a I.C. criou o hábito de estudo sistemático e aumentou a minha dedicação e interesse como estudante.

Vale destacar que o conhecimento adquirido é um elemento muito recorrente (presente em $76,9 \%$ das respostas), exibindo narrativas - como podem ser observadas nos excertos apresentados - sobre habilidades/saberes específicos do tema de pesquisa, como leitura, escrita, interpretação e produção textual, e o aprender a pesquisar. Para isso, os jovens estudantes apontam uma maior dedicação e comprometimento com os estudos, permeados pela interdisciplinaridade e pela experiência adquirida em feiras e eventos científicos. Além da contribuição para as matérias técnicas, enfatizavam a contribuição do tema de pesquisa para a sociedade, apontando uma valorização do E.M..

\section{Corte temporal}

O corte temporal, identificado nas respostas dos jovens estudantes, foi possível por existir uma centração sobre o problema de pesquisa e, atrelado a isso, ao próprio processo metodológico científico da I.C.. Percebeu-se que os estudantes passaram a fazer coisas que não faziam antes, valorizar coisas antes não valorizadas, compartilhar saberes por meio de novos hábitos incorporados por meio de mudanças ou de aquisição de novas concepções; Peirce (2012) chama tais transformações de mudança de comportamento que acontecem por meio de novas mediações ou representações entre o sujeito e o objeto, no caso entre o estudante e os saberes escolares. Como efeito, foi possível identificar a presença de um corte sobre o passado e o contexto deixa evidente que houve um começo real no processo de orientação:

JE1: Passei a me empenhar mais e a dar mais valor aos estudos. [...] a ter uma visão mais crítica perante as pessoas e o mundo. Minha iniciação científica fez com que eu mudasse meus hábitos perante as tecnologias e me policiasse mais no que diz respeito ao tempo gasto conectada em redes sociais. Ademais, despertou meu interesse em programação. JE2: [...] me tornei mais dedicada, esforçada e aprendi a me expressar melhor. JE3: mudei os métodos de pesquisas que utilizava antes. JE4: por causa do projeto houve um entendimento maior das matérias técnicas. JE5: O que muda é que aprende a solucionar problemas melhor, mas não comportamento. JE6: [...] visto que quando se inicia uma pesquisa sua percepção para novas problemáticas começam a surgir. [...] pois houve uma mudança significativa quando a minha percepção em problematizar sobre alguns assuntos começou a buscar hipóteses de se obter respostas. JE8: [...] antes para mim a I.C. era só o desenvolvimento de projetos, mas hoje em dia eu digo que a I.C. ajuda jovens a se tornarem pessoas. [...] através da I.C. obtive conhecimento sobre algo novo e comecei a 
me importar mais com outras culturas e diversidade. JE13: [...] pois me fez ter perspectivas diferentes de certos assuntos.

Nesse ínterim, as narrativas enunciadas pelos jovens ex-orientados são produzidas e expostas pelas percepções vividas na I.C.. Esta se constitui como um elemento "novo" que foi, dentro de um processo, testado e re-testado várias vezes pelos jovens estudantes, proporcionando mudanças de comportamento percebidas nos seguintes pontos chaves na configuração do estudar, ou seja: dedicação, empenho, responsabilidade e maneira de ver a ciência.

\section{Atratores e ruídos}

Foi possível identificar a existência de elementos presentes nas respostas de todos os jovens estudantes e em todas as categorias, tanto nos registros de caderno de campo quanto nas respostas aos questionários, que ao mesmo tempo faziam referência ao passado, compeliam o presente e projetavam o futuro em um ir e vir dinâmico, chamados de atratores e ruídos. Esses elementos moldaram uma forma de agir e pensar de tal maneira que os esforços de todo o processo direcionaram-se para a incorporação de conbecimentos, na interação da I.C. com a sociedade e por proporcionar aos jovens estudantes a oportunidade de descobertas, experimentações e escolhas.

A presença de indícios de que os jovens perceberam a incorporação de conbecimentos durante e após o processo de orientação não foi algo isolado, mas atrelado a contribuições para a área técnica, na interpretação textual, na forma de estudar e na maneira de expressar para outro o que se aprendeu:

JE1: [...] melhorar a interpretação de textos e na aplicação da área técnica. JE2: [...] melhorou minha interpretação e produção textual, assim como minhas apresentações em público. [...] devido ao desenvolvimento de uma melhor interpretação textual. JE3: [...] mudei os métodos de pesquisas que utilizava antes.

A interação da I.C. com a sociedade - tomando como base de explicação a cultura juvenil e suas diversas características - é pressuposta ou identificada pelo posicionamento do jovem perante a sociedade e a si mesmo (DAYRELL; CARRANO, 2014). A percepção de que a I.C., de acordo com a pesquisa realizada, contribuiu de alguma forma para a sociedade, mostrou aos jovens por meio da Linguagem Cultural que eles podem ser produtores culturais e não apenas meros consumidores e reprodutores. Nesse contexto educacional uma forma de linguagem é incorporada, a I.C., diferente da música, da dança, do vídeo e do próprio corpo, comumente manifestados fora desse contexto; a I.C. insere, ao mesmo tempo, o já vivido e dá forma a uma nova maneira de mediação. Dessa maneira, há um Grupo Cultural (os que vivenciam a I.C.) entre esses jovens, que permitiu a entrada deles no meio público, ganhando visibilidade no meio escolar e entre os colegas, pois foram atores nesse processo que além de acadêmico, frisa-se, é cultural.

JE1: Sim. Me ver inserida nesse mundo da iniciação científica, feiras e eventos (o que não tem no Ensino Médio em outras instituições) fez com que eu sentisse que estava contribuindo de alguma forma na sociedade e me fez querer continuar nesse instituição que abre um leque de possibilidades que outras instituições não abrem. JE2: Ajudou-me a compreender melhor a inserção das 
tecnologias na nossa sociedade e como observar de modo crítico como nos relacionamos com ela. JE10: Sim, porque me fez pensar mais nos outros, ter uma visão mais ampla sobre o mundo e como a representatividade é necessária. [...] antes era como uma obrigação e agora vejo como uma forma de mudar para melhor a vida das pessoas, levando informação. JE12: Tornou mais claro para mim quais são as funções da Educação Física, pois a pesquisa procurava estabelecer uma forma de trabalhar as inteligências múltiplas a partir do conteúdo programático desenvolvido para o IFMS, ao mesmo tempo em que sugeria mudanças que pudessem aumentar a eficiência do ensino. JE13: Poder disponibilizar conteúdo de forma rápida e fácil para as pessoas e abordar assuntos pouco tratado pelas pessoas.

Não obstante, a Sociabilidade como uma das chaves analíticas da Condição Juvenil, proposta por Carrano e Dayrell (2014), permite compreender que a dinâmica de relações vividas por esses jovens esteve repleta de descobertas, experimentações e escolhas. Contudo, um elemento importante para isso é a autonomia, conseguida apenas se o sujeito estiver disposto a conciliar as relações estabelecidas com quem ele possui afinidade, não apenas nos momentos de lazer, mas também no que diz respeito às obrigações acadêmicas. Essa aceitação de enfrentamento possibilita dar significado ao que os jovens vivenciam e gerenciam e estão dotadas de interações afetivas e simbólicas, ou seja, carregadas de sentidos.

JE8: A aprendizagem, a forma de organização, as leituras e fichamentos, o vocabulário, as apresentações, o desenvolvimento do projeto. JE9: [...] capacidade de escrever e me sentir na frente de outros colegas de sala quando assunto era metodologia científica. JE12: Contato com uma nova área. Oportunidade de aprendizado na exposição oral e escrita do conteúdo estudado. Maior responsabilidade como estudante. JE4: Além do aprendizado com o próprio projeto e as aplicações práticas das matérias estudadas no IFMS, foi uma experiência que será importante no futuro, principalmente na faculdade. JE5: Como fizemos um estudo de caso, que pretendia verificar "relação" do nível de atividade física com a qualidade de vida dos estudantes. Foi positivo por verificar que os jovens não têm se preocupado em realizar atividade e/ou exercício físico para melhorar a saúde. JE7: Sim, as feiras de ciências são realizadas oralmente, melhorando a comunicação e relações pessoais.

Diante desta análise dos dados, percebeu-se que a incorporação de conhecimentos e a interação da I.C. com a sociedade constituíram-se como atratores durante o processo de orientação, já que não eram elementos apontados como algo desejado no início da orientação, mas que surgiram e consolidaram-se na própria interação. Contudo, a oportunidade de descobertas, experimentações e escolhas foi identificada como ruido, pois as dificuldades presentes e enfrentadas no processo foram provocadores de mudanças na dinâmica interna da orientação (DEBRUN, 1996), isso é percebido pelas dificuldades apontadas.

JE3: Pouco tempo para pesquisar e elaborar mais conteúdos (atividades). JE4: Acredito que a não ampliação do grupo de análise, para propagar a prática de atividade e/ou exercício físico para melhorar a saúde para um grupo maior. JE7: A pressão. JE8: Creio que os pontos negativos foram as dificuldades em conciliar a I.C. e as disciplinas mais as minhas atividades fora da escola. JE9: 
Desencontros para organização de orientações. JE11: Um ponto negativo foi que o projeto deu uma sobrecarregada, já que tínhamos que fazer provas e trabalhos também.

As dificuldades em conciliar a I.C. com as disciplinas escolares e as atividades exteriores à escola não provocaram rupturas ou interromperam o processo de orientação, mas fez com que houvesse empenho e dedicação em um trabalho que exigiu uma reorganização dos estudantes, percebida na mudança da forma de estudar e na capacidade de conciliar a I.C. com as disciplinas escolares e as atividades exteriores à escola.

\section{CONSIDERAÇÕES FINAIS}

Atendendo aos objetivos da pesquisa e das categorias de análises, podemos considerar que o processo educacional na visão dos jovens estudantes, em um ambiente de I.C. de E.M., destaca-se pelas contribuições advindas do próprio processo de orientação, baseado na Semiótica e na Auto-organização e considerando as perspectivas dos jovens estudantes calcadas na Sociologia da Juventude, percebida pela ênfase dada à interação e às expectativas atingidas por meio da experiência e do conhecimento adquirido.

$\mathrm{Na}$ formação como estudante o enfoque dirige-se à melhora relacionada ao empenho nos estudos, na percepção do saber adquirido pela aprendizagem, destacando a possibilidade de "perceberem" esses saberes adquiridos. Verificou-se que os jovens estudantes passaram a vivenciar e valorizar coisas novas, a partilhar saberes por meio de novos hábitos adquiridos pelas mudanças ou aquisição de novas concepções, destacando o corte temporal sobre o passado o que permitiu um novo começo.

Sendo assim, identificou-se a presença da incorporaşão de conhecimentos, da interaşão da I.C. com a sociedade e de descobertas, experimentações e escolhas como elementos comuns no processo de orientação, em movimento dinâmico tanto nos registros de caderno de campo quanto nas respostas aos questionários. As respostas apresentaram, também, uma crítica ao acúmulo de atividades, percebido pelas dificuldades apontadas em conciliar a I.C. com as disciplinas escolares e com as atividades exteriores à escola, porém configuradas como ruidos já que proporcionaram uma reorganização na forma dos jovens dedicarem-se aos estudos.

Nesse ínterim, analisou-se o processo educacional em um ambiente de pesquisa de E.M. onde há um elo frágil da pesquisa, ou seja, no seio escolar. Outrossim, os resultados mostraram a contribuição da I.C. para um trabalho direcionado na busca de conhecimentos, na interação da I.C. com a sociedade e na potencialidade de proporcionar aos jovens estudantes a oportunidade de vivenciar uma educação que realmente fizesse diferença em suas vidas.

\section{REFERÊNCIAS}

ALVES-MAZZOTTT, Alda J. GEWANDSZNAJDER, Fernando. O Método nas Ciências Naturais e sociais - Pesquisa Quantitativa e Qualitativa. 2. ed. Pioner, São Paulo SP, 1999.

BARDIN, Laurence. Análise de Conteúdo. Tradução de Luís Antero Reto e Augusto Pinheiro. Lisboa, Portugal: Edições 70, 1977.

CARRANO, Paulo. Identidades Culturais Juvenis e escolas: arenas de conflitos e possibilidades. Diversia, Valparaíso, n. 1, p. 159-184, abr. 2009. 
CARRANO, Paulo. Jovens, Escolas e Cidades: Desafios à autonomia e à convivência. Revista Teias, Rio de Janeiro, v. 12, n. 26, p. 07-22, set./dez. 2011.

DAYRELL, Juarez. A escola como espaço sócio-cultural. Múltiplos olhares sobre educação e cultura, Belo Horizonte, v. 194, p. 136-162, 1996.

DAYRELL, Juarez. Juventude e escola. Estado do Conbecimento, Brasília, n. 7, p. 28-28, 2002.

DAYRELL, Juarez; CARRANO, Paulo. Juventude e Ensino Médio: quem é este aluno que chega à escola. In: DAYRELL, J.; CARRANO, P.; MAIA, C. L. (org.). Juventude e Ensino Médio: sujeitos e currículos em diálogo. Belo Horizonte: Editora UFMG, 2014, p. 101-134.

DEBRUN, Michel. 1) A ideia da auto-organização. 2) A dinâmica da auto-organização primária. In: DEBRUN, Michel; GONZALES, Maria E. Q; PESSOA JR., Osvaldo (org.). Auto-organização: estudos interdisciplinares. Campinas: UNICAMP - Coleção CLE, v.18, 1996, p. 3-24.

DUTRA, Ítalo M. (org.) et al. Trajetórias criativas: jovens de 15 a 17 anos no ensino fundamental: uma proposta metodológica que promove autoria, criação, protagonismo e autonomia. Caderno 7: iniciação científica. Brasília: Ministério da Educação, 2014.

FEIXA, Carlos. De jóvenes, bandas e tribus. Barcelona: Ariel, 1998.

FEIXA, Carlos. Del reloj de arena al reloj digital: sobre las temporalidades juveniles. Jovenes, Revista de Estudios sobre Juventud, México, ano 7, n. 19, p. 6-27, jul./dez., 2003.

MARTINS, Carlos H. dos S; CARRANO, Paulo C. R. A escola diante das culturas juvenis: reconhecer para dialogar. Educação, Santa Maria, v. 36, n. 1, p. 43-56, jan./abr. 2011.

NUNES, Brasilmar Ferreira; WELLER, Wivian. A juventude no contexto social contemporâneo. Estudos de Sociologia, Recife, v. 9, n. 2, p. 43-57, 2003.

GOMES-DA-SILVA, Eliane; KUNZ, Elenor; SANT'AGOSTINO Lucia H. F. Educação (física) infantil: território de relações comunicativas. Revista Brasileira de Ciência do Esporte, Florianópolis, v. 32, n. 2-4, p. 29-42, dez. 2010.

LAKATOS, Eva M.; MARCONI, Marina de A. Fundamentos de metodologia científica. São Paulo: Atlas, 2010.

PAIS, José M. A construção sociológica da juventude - alguns contributos. Análise Social, Lisboa, vol. XXV (105-106), p. 139-165, 1990. Disponível em:<http://www.jstor.org/stable/41010794>. Acesso em: 04 nov. 2019.

PAIS, José M. Nas rotas do quotidiano. Revista Crítica de Ciências Sociais, Lisboa, n. 37, p. 105-115, jun. 1993.

PAIS, José M. A Juventude como Fase de Vida: dos ritos de passagem aos ritos de impasse. Saúde Social, São Paulo, v.18, n.3, p.371-381, 2009. Disponível em:<https://doi.org/10.1590/S010412902009000300003>. Acesso em: 04 nov. 2019.

PAIS, José M. A esperança em gerações de futuro sombrio. Estudos avançados, São Paulo, v. 26, n. 75, p. 267-280, 2012.

PEIRCE, Charles S. Escritos coligidos. Tradução de Armando Mora D’Oliveira e Sergio Pomerangblum. São Paulo: Abril Cultural, 1974.

PEIRCE, Charles S. Semiótica. Tradução de José Teixeira Coelho Neto. 4. ed. São Paulo: Perspectiva, 2012.

PERALVA, Angelina. O jovem como modelo cultural. Revista Brasileira de Educação, São Paulo, ANPED, n. 5/6, maio/ago., set./dez., n. 5/6, p. 15-24, 1997. 
SPOSITO, Marília P. Estudos sobre juventude e educação. Revista Brasileira de Educação, São Paulo, mai./ago., set./dez., n. 5 e 6, p. 37-52, 1993.

SPOSITO, Marília P. Algumas reflexões e muitas indagações sobre as relações entre juventude escola no Brasil. In: ABRAMO, Helena; BRANCO, Pedro P. M. (org.). Retratos da juventude brasileira: análises de uma pesquisa nacional. São Paulo: Instituto Cidadania/Editora Fundação Perseu Abramo, 2005. p. 87-128.

SPOSITO, Marília P. (coord.). Espaços públicos e tempos juvenis: um estudo de ações do poder público em cidades de regiões metropolitanas brasileiras. São Paulo: Global, 2007.

STENHOUSE, Lawrence. La investigación como base de la ensenãnza. 2. ed. Tradução para fins didáticos: Mauro Betti. Madrid: Morata, 1993.

VILLAS, Sara.; NONATO, Symaira. Juventude e projetos de futuro. Belo Horizonte: UFMG, 2014.

WELLER, Wivian. A atualidade do conceito de gerações de Karl Mannheim. Sociedade e Estado, Brasília, v. 25, n. 2, p. 205-224, 2010.

SZYMANSKI, Heloisa; ALMEIDA, Laurinda R. de; PRANDINI, R. C. A. R. A entrevista na pesquisa em educação: a prática reflexiva. 4 ed. Brasília: Plano Editora, v. 4, 2011.

Submetido em julho de 2020

Aprovado em janeiro de 2021

\section{Informações dos autores}

Alan Rodrigo Antunes

IFMS - Instituto Federal de Educação, Ciência e Tecnologia de Mato Grosso do Sul, Campus Três Lagoas E-mail:alan.antunes@ifms.edu.br

ORCID: https://orcid.org/0000-0003-1687-694X

Link Lattes: http://lattes.cnpq.br/2241458866527565

Márcia Regina Canhoto de Lima

UNESP - Universidade Estadual Paulista, Campus Presidente Prudente

E-mail:marcia.rc.lima@unesp.br

ORCID: https://orcid.org/0000-0003-2435-923X

Link Lattes: http://lattes.cnpq.br/9708235443134366 